\title{
Studies in the cycloproparene series: cycloaddition reactions of diarylmethylidenecycloproparenes ${ }^{\dagger 1}$
}

\author{
Brian Halton, ${ }^{\ddagger *}$ Andrew J. Kay, ${ }^{\ddagger}$ Aileen T. McNichols, ${ }^{\S}$ Peter J. Stang, ${ }^{\S *}$ Yitzhak \\ Apeloig, ${ }^{\text {q*}}$ Roland Boese, ${ }^{+*}$ Andreas H. Maulitz, ${ }^{+}$and Thomas Haumann ${ }^{+}$
}

\begin{abstract}
${ }^{\ddagger}$ School of Chemical and Physical Sciences, Victoria University of Wellington, PO Box 600, Wellington, New Zealand, and the Departments of Chemistry at ${ }^{\S}$ The University of Utah, Salt Lake City, Utah 84112, USA

Technion - Israel Institute of Technology, Haifa 32000, Israel, and ${ }^{+}$The University of Essen, $D$ 45117 Essen, Germany

‡E-mail: brian.halton@vuw.ac.nz
\end{abstract}

It is a pleasure to dedicate this paper to Professor Don Cameron in recognition of his outstanding contribution to Australasian chemistry

(received 09 May 01; accepted 31 Jul 01; published on the web 08 Aug 01)

\begin{abstract}
Diarylmethylidenecyclopropanaphthalenes $\mathbf{4 b - d}$ add diphenylisobenzofuran (DPIBF) and $\alpha$ pyrone across the exocyclic double bond to give ring expanded products 11b-d and 13b-d that result from subsequent relief of ring strain in the non-isolable spirocyclic intermediates $\mathbf{1 0}$ and 12, respectively. The benzene homologues $\mathbf{3 b}$ and $3 \mathbf{c}$ add DPIBF across the bridge bond to give the norcaradiene adducts 19b and 19c.
\end{abstract}


These observations match expectation based upon the loss of aromaticity in the arene moiety caused by addition to the bridge bond. The cycloadditions have been studied also by ab initio quantum mechanical calculations at the MP2/6-31G(d)//HF/6-31G(d) and MP3 levels of theory. With acetylenic(phenyl)-iodonium triflates 14 formal [2+2] cycloaddition to the exocyclic $\pi$

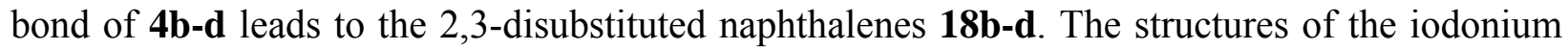
salt 18d and the bridge adduct 19b are confirmed from structure determination by X-ray crystallographic methods.

Keywords: $\mathrm{Ab}$ initio calculations, strained aromatics, acetylenic-iodonium salts, crystal structures, cyclobutanes, Diels-Alder cycloaddition, norcaradienes

\section{Introduction}

The class of strained aromatic hydrocarbons known as the cycloproparenes, ${ }^{2}$ and illustrated by the parent molecule $1 H$-cyclopropabenzene (1) and $1 H$-cyclopropa[b]naphthalene (2), has provided a wealth of fascinating chemistry since the first authenticated derivative was reported in 1964.

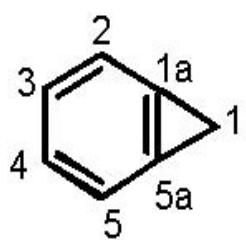

1

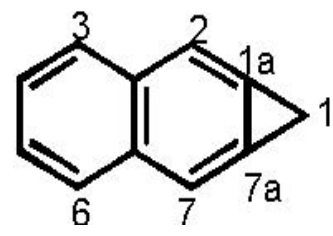

2

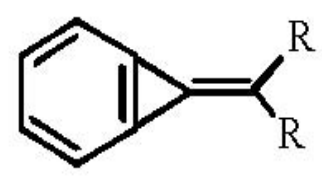

3

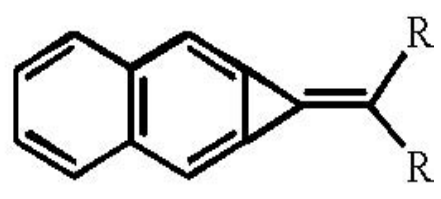

4 
In particular, the pKa of $\mathbf{1}$ is estimated ${ }^{3}$ as $c a .36$ and the C-1 cyclopropabenzenyl anion and its naphthalenyl analogue can be generated and used in synthesis. ${ }^{1,4-7}$ Indeed, it is through use of these $\mathrm{C}-1$ anions, e.g. 5, that the transformation a cycloproparene $\mathrm{C}-1$ from $\mathrm{sp}^{3}$ to $\mathrm{sp}^{2}$ with an attendant exocyclic double bond has been achieved, thereby generating the intriguing class of unusual compounds known as the alkylidenecycloproparenes, e.g. 3 and 4. ${ }^{2,4-7}$ Thus anion 5 is easily converted via 6 into a-silyl anion 7 that undergoes Peterson olefination with a range of non-enolisable aldehydes or ketones to give 4 (Scheme 1).

The alkylidenecycloproparenes $\mathbf{3}$ and $\mathbf{4}$ have attracted considerable attention themselves in recent times as unusual, highly strained synthetic molecules whose physical characteristics have been assessed and whose chemical behaviour has been investigated with a variety of reagents. ${ }^{2-4}$ Nonetheless, the behaviour of the compounds in cycloadditions has not been addressed previously. ${ }^{8}$ We report here an experimental and theoretical study of the $[2+4]$ cycloadditions of the selected methylidenecycloproparenes $\mathbf{3 b}, \mathbf{c}$ and $\mathbf{4 b}$-d with the dienes diphenylisobenzofuran (DPIBF) and $\alpha$-pyrone, as well as the behaviour of the naphthalene derivatives with the markedly electron deficient acetylenic(phenyl)iodonium triflate 14.

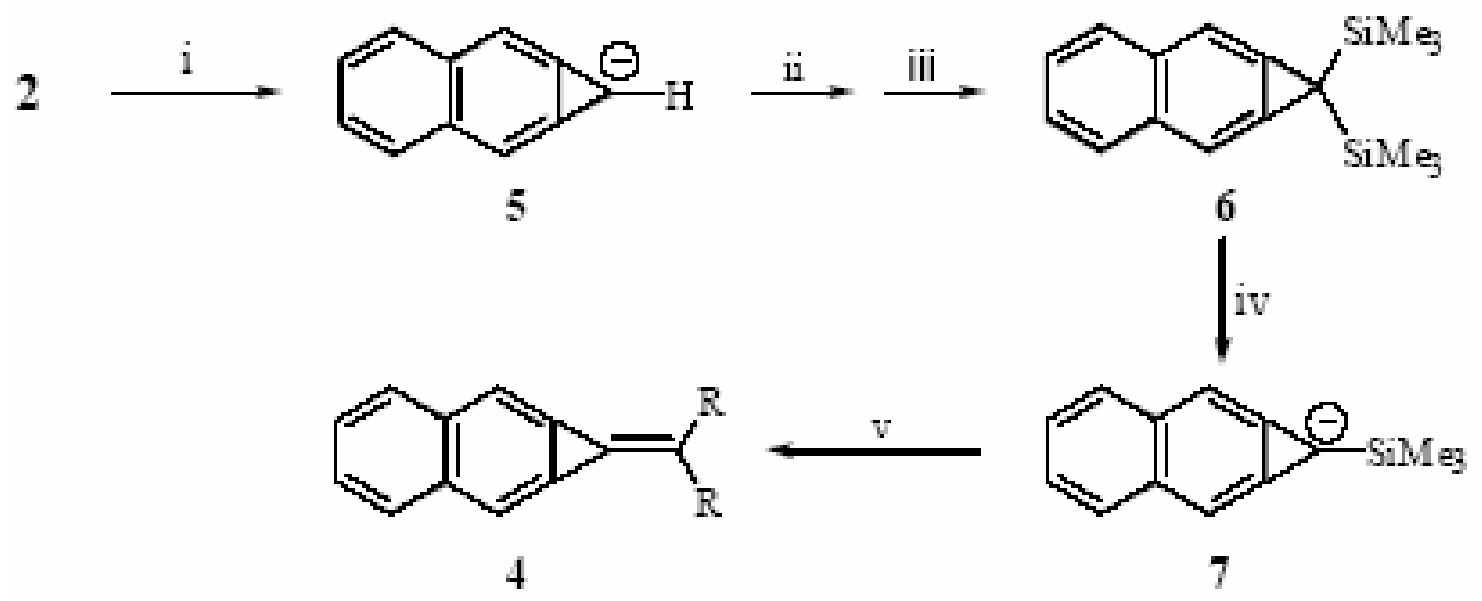

Reagents: i) BuLi; ii) TMSCl; iii) $\mathrm{BuLi}, \mathrm{TMSCl}$; iv) $\mathrm{KOBu}^{t}$; v) $\mathrm{R}_{2} \mathrm{CO}$

\section{Scheme 1}


X-ray crystallographic data that confirm the structures of products $\mathbf{1 8 d}$ and $\mathbf{1 9 b}$ are also reported. The theoretical calculations have employed ab initio quantum mechanical calculations methods at the MP2/6-31G(d)// HF/6-31G(d) level for studying the reactions of the unknown ${ }^{4}$ parents 3a and 4a with furan and the semiempirical method was used for calculating the reactions of the diphenyl compounds $\mathbf{3 b}$ and $\mathbf{4 b}$ with DPIBF as actually examined experimentally.

\section{Results and Discussion}

The cycloproparene hydrocarbons $\mathbf{1}$ and $\mathbf{2}$ have available two potential sites for cycloaddition, namely the $\mathrm{C} 1 \mathrm{a}-\mathrm{C} 5 \mathrm{a}$ (or $7 \mathrm{a}$ ) bridge bond and the three-membered ring $\sigma$ bond. With the HOMO of 1 located at the bridge and $\mathrm{C} 3-\mathrm{C} 4$ bonds, it is not surprising that the molecule behaves as an electron rich dienophile and adds dienes across the bridge resulting in a range of derivatives that transform into other interesting compounds. ${ }^{2}$ However, cycloaddition across the strained threemembered ring $\sigma$ bond can also occur especially with four-electron electrophilic dipolar reagents. ${ }^{9}$ With DPIBF, 1 displays both reaction modes dependent on the specific conditions employed. Addition to the bridge results in both endo and exo adducts 8 while ring opening gives 9 (Scheme 2). ${ }^{10}$

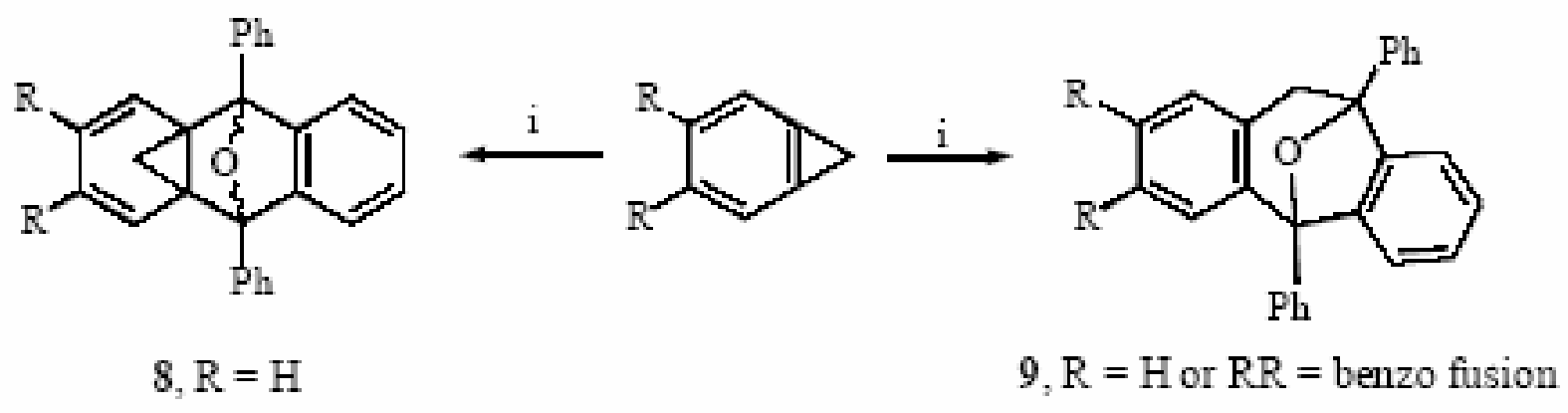

Reagent: i) diphenylisobenzofuran -DPIBF

\section{Scheme 2}


In comparison, cyclopropanaphthalene 2 predominantly opens the three-membered ring by addition across the $\sigma$ bond thereby avoiding the high energy orthoquinodimethane intermediate demanded from loss of aromaticity in both six-membered rings. ${ }^{9,10}$

In comparison to the above, the methylidene derivatives $\mathbf{3}$ and $\mathbf{4}$ offer the exocyclic double bond as an additional site for reaction. It is, therefore, more than idle curiosity that demands an answer to the question of regioselectivity in the cycloadditions of these compounds. The outcome must result in novel products that likely transform into other interesting materials irrespective of the site of addition and we now report on these.

\section{Experimental Study}

The readily available and representative diarylmethylidenecyclopropanaphthalenes $\mathbf{4 b},{ }^{6} \mathbf{4} \mathbf{c},{ }^{11}$ and 4d, ${ }^{12}$ and the more difficultly obtained benzenoid homologues $3 \mathbf{b}^{6}$ and $3 \mathbf{c}^{11}$ were selected for examination and prepared according the published procedures.

When heated with DPIBF in dry degassed toluene for several days $\mathbf{4 b}$ provides a pale yellow solid 1:1 addition product the ${ }^{13} \mathrm{C}$ NMR of which does not show the characteristically shielded C2/7 resonances (105-115 ppm) of the cycloproparene precursor. ${ }^{2}$ This clearly implies the absence of $\mathbf{4} \mathbf{b}$ and any product in which the cycloproparenyl moiety is retained. Moreover, the proliferation of aromatic carbon resonances (Experimental) demands a lack of symmetry. The product is identified as the cyclobutanaphthalene $11 \mathrm{~b}(55 \%)$. The ${ }^{13} \mathrm{C}$ NMR clearly displays three of the four cyclobutarenyl carbons $\left(\delta 76.1, \mathrm{sp}^{3} ; 150.3\right.$ and 163.1 , aromatic $\left.\left.\mathrm{sp}^{2}\right)\right]$ and the side-chain carbonyl carbon is at $\delta$ 198.2; IR absorptions for the side-chain conjugated carbonyl and the exocyclic olefinic bond are recorded at 1665 and $1738 \mathrm{~cm}^{-1}$, respectively. ${ }^{13}$ In like manner, reaction of the dimethoxy $\mathbf{4 c}$ and bis(trifluoromethyl) $4 \mathbf{d}$ lead to the corresponding cyclobutarenes 11c (32\%) and 11d (42\%). 
Liotta et al. have reported that Diels-Alder cycloadditions show an enhanced rate when conducted in ethylene glycol particularly with hydrophobic diene/dienophile pairs and, additionally, the influence of salt effects on Diels-Alder cycloadditions has been reviewed. ${ }^{14}$ In the cases of additions of $\mathbf{4 b} \mathbf{b}-\mathbf{d}$ to DPIBF, ethylene glycol facilitates the reactions as they are essentially complete in $7 \mathrm{~h}$ with product yields increased to $42-62 \%$.

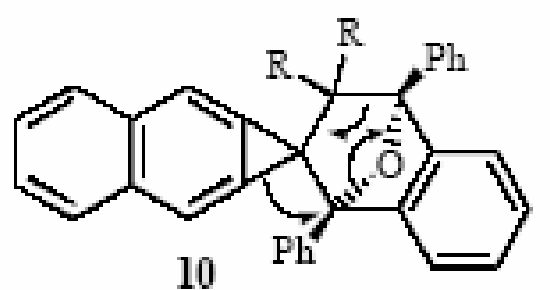

10

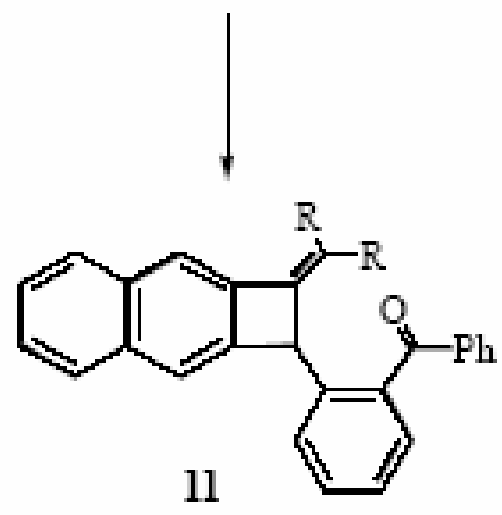

Reagent. i) DPIBF
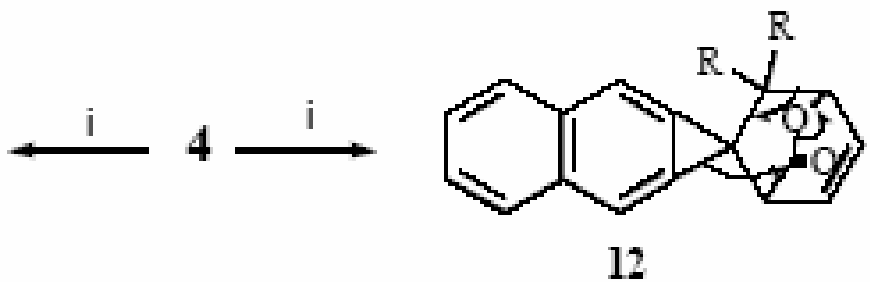

a: $\mathrm{R}=\mathrm{H}$

b: $\mathrm{R}=\mathrm{Ph}$

c: $\mathrm{R}=p-\mathrm{MeOC}_{6} \mathrm{H}_{4}-$ d: $\mathrm{R}=m-\mathrm{CF}_{3} \mathrm{C}_{6} \mathrm{H}_{4}-$

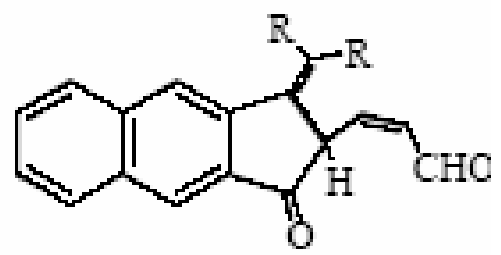

13

\section{Scheme 3}


The formation of the cyclobutarenyl products 11 shows that cycloproparenes 4 resist addition to both the bridge and strained $\sigma$ bonds and that any addition across the exocyclic double bond must result in subsequent rearrangement of the product. The formation of $\mathbf{1 1}$ is best rationalized from initial [2+4] addition across the exocyclic $\pi$ bond to give the novel spirocycles $\mathbf{1 0}$. These highly strained compounds are able to release strain by way of cycloproparenyl - cyclobutarenyl ring expansion ${ }^{2,7}$ with concomitant cleavage of the ether bridge and diaryl ketone formation, as depicted in Scheme 3. Analogous ether bridge cleavage has recently been reported by Kitamura et al. for DPIBF adducts of norbornynes. ${ }^{15}$ While the Diels-Alder cycloaddition with 4 proceeds to a strained (and transient) cycloadduct, it does so without involving the bridge bond and the (presumably) higher energy orthoquinodimethane, cf. 8 (Scheme 2 and below).

The reactions of $\mathbf{4 b}$-d with $\alpha$-pyrone also provide product that is best rationalized from additon to the exocyclic double bond of the substrate. Again the use of ethylene glycol in place of toluene as solvent is notably beneficial, viz. the reaction period for $\mathbf{4 b}$ reduces from days to 7 $\mathrm{h}$ and the yield increases from 12 to $50 \%$. The products are identified as the substituted benzindanones 13b-d (Experimental) that arise from comparable rearrangement of the initially formed spirocycles 12. In these cases rapid migration of the three-membered ring $\sigma$ bond to the carbonyl carbon triggers formation of the $(Z)$-enal functionality with ring expansion from three to five-members (Scheme 3). Opening of the lactone moiety in this way is presumed to be facile as diene products resulting from the more traditional decarboxylation ${ }^{16}$ were not observed. 


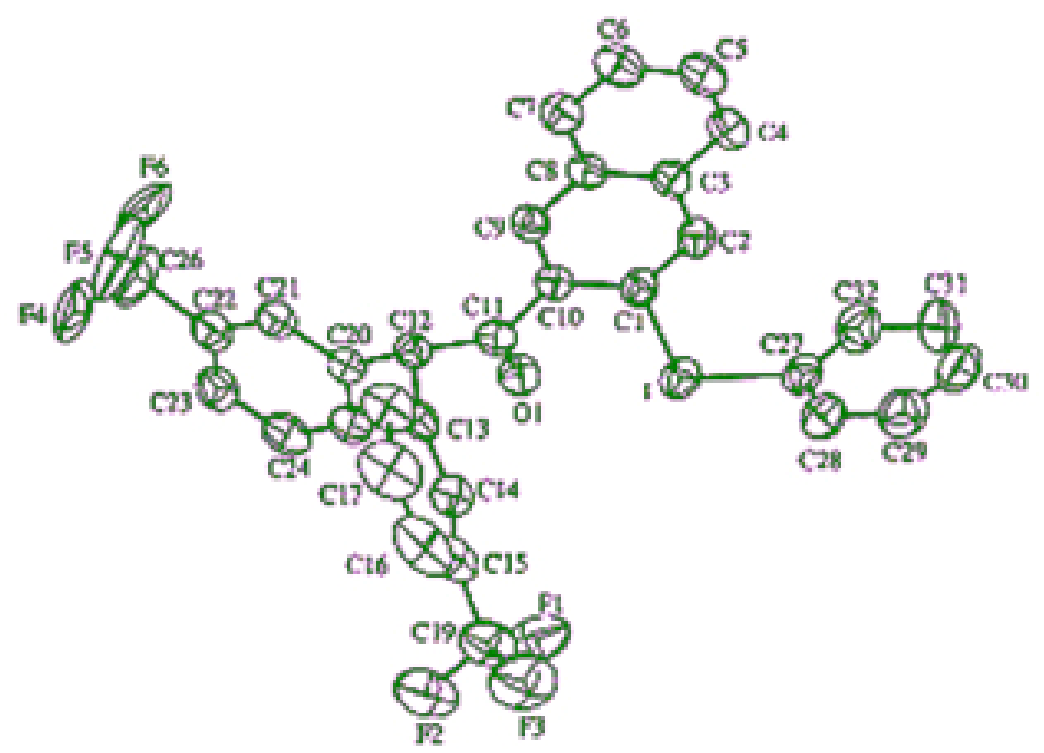

Figure 1. ORTEP diagram of the cation of $\mathbf{1 8 d}$ with crystallographic numbering.

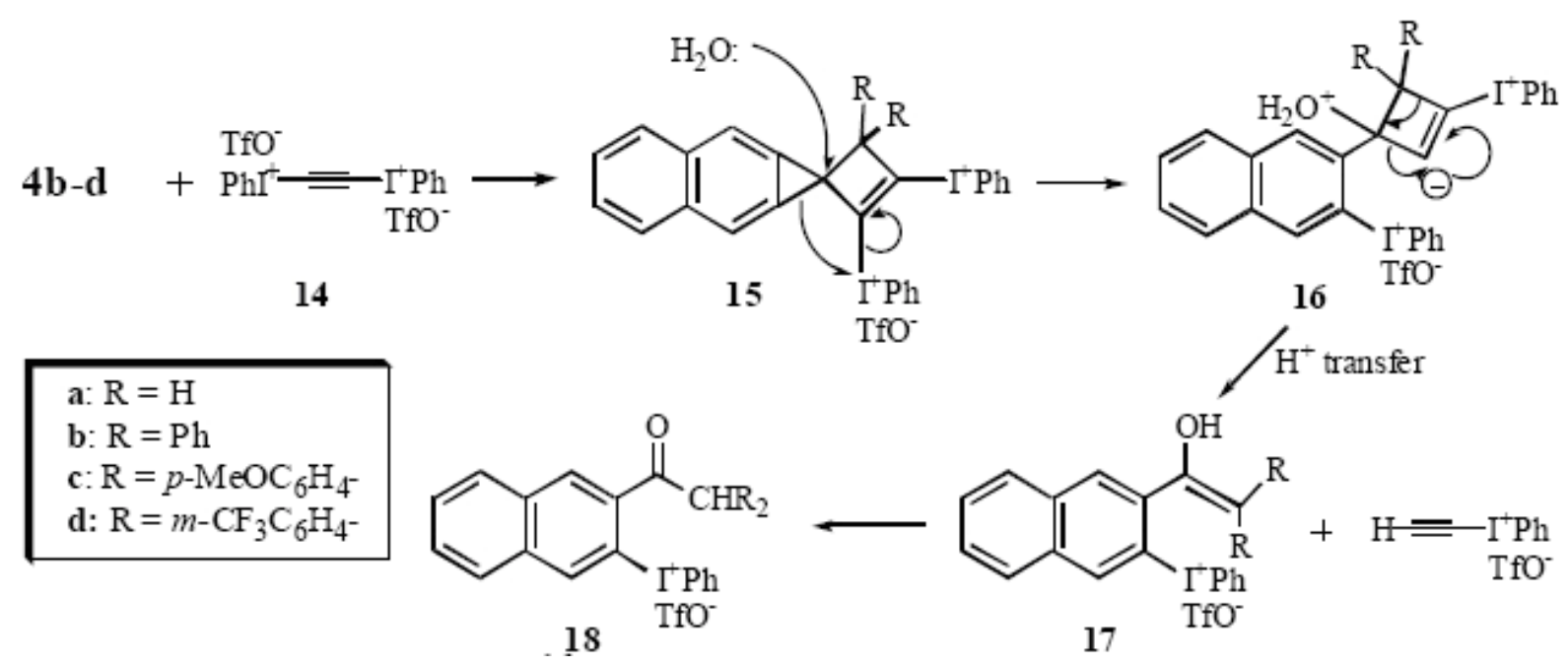

Scheme 4 
It was of also interest to see if the methylidene derivatives 4 would behave as electron-rich donors in $[2+2]$ reactions. In this context the strong electron withdrawing capacity of the iodonium moiety seemed ideal ${ }^{17}$ particularly in light of the availability of the acetylenic (phenyl)iodonium triflate 14. ${ }^{18}$ Reactions of $\mathbf{4 b}$-d with bis-iodonium salt $\mathbf{1 4}$ proceed at ambient temperature over $7 \mathrm{~h}$ to give the naphthyl iodonium triflates 18b-d in yields of $40-60 \%$. The ${ }^{1} \mathrm{H}$ NMR spectra of 18b-d each display a single methine proton as the only aliphatic signal $(\delta 2.35-$ 2.45) while the IR spectra show conjugated ethanone stretching frequency at ca. $1650 \mathrm{~cm}^{-1}$. The structure of the bis(trifluoromethyl) derivative 18d has been confirmed by single crystal X-ray analysis (see Fig. 1 and below). The route by which $\mathbf{4}$ is transformed into $\mathbf{1 8}$ is less obvious than for the diene additions. Nonetheless, interaction with the exocyclic double to give the spirohexenes 15 is plausible (Scheme 4). Subsequent reaction of these with water during workup triggers three-membered ring expansion with ejection of iodonium acetylide as shown from 16. This leads to enol $\mathbf{1 7}$ and mono-iodonium triflate after proton transfer. Enol-keto tautomerism in 17 accounts for 18. The proposal is supported by isolation of the methoxy analogue of enol ether $\mathbf{1 7} \mathbf{b}$ when the reaction was performed in the presence of methanol.

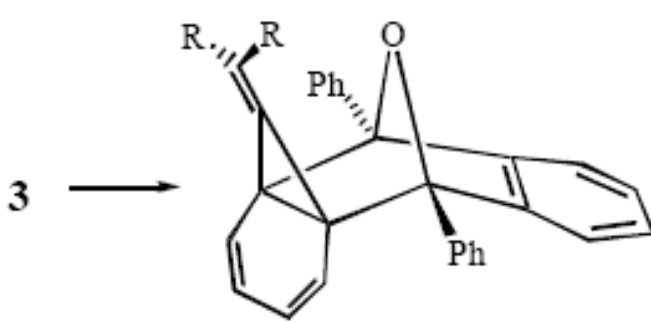

19

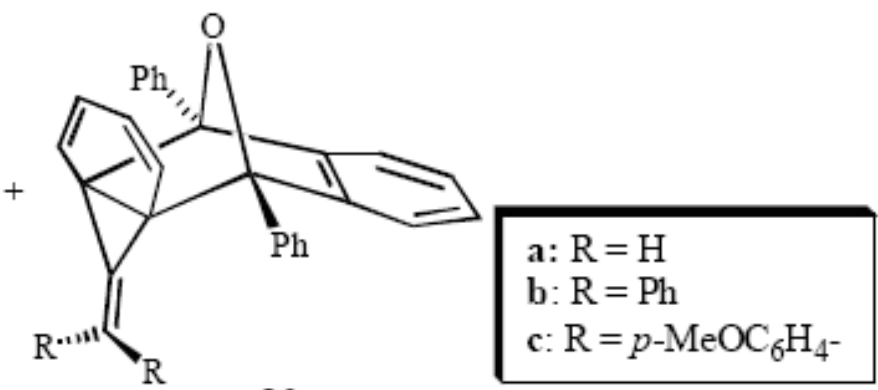

20

\section{Scheme 5}


In contrast to the foregoing, we find that the methylidenecyclopropabenzenes 3 are more reluctant to undergo cycloaddition. While ethylene glycol again facilitates the reactions in comparison to toluene, the cycloadditions of $3 \mathbf{b}$ and $3 \mathbf{c}$ to DPIBF still require $24 \mathrm{~h}$ at $120^{\circ} \mathrm{C}$ rather that the $7 \mathrm{~h}$ at $110^{\circ} \mathrm{C}$ for $\mathbf{4 b}-\mathbf{d}$. These reactions return some unchanged DPIBF but both $\mathbf{3 b}$ and 3c give a single crystalline 1:1 cycloadduct in a yield of 48 and 27\%, respectively. That these compounds are propelladienes 19 or 20 (Scheme 5) is immediately obvious from the ${ }^{1} \mathrm{H}$ NMR spectra as they each exhibit an AA'BB' pattern in the olefinic region ( $\delta 5.65$ and 6.11$)$, and they do not show a carbonyl stretching frequency in the IR. However, the orientation of these Diels-Alder adducts as endo 19 or exo 20 with respect to the fused benzenoid ring of 3 (cf. Scheme 2) is not obvious and there are no in-built structural features that allow for easy differentiation. As noted above, 1 adds DPIBF across the bridge bond to give both endo and exo $[2+4]$ products as well as the unsymmetrical adduct from addition to the strained $\sigma$ bond (Scheme 2); ${ }^{10}$ it provides no precedent. Determination of the structure of product from $\mathbf{3 b}$ depended upon X-ray crystallographic methods and these show the compound to be endo 19b with the oxygen atom and the three-membered ring syn (see Fig. 2 and below); that from 3c is assigned as 19c by analogy.

Unlike DPIBF, $\alpha$-pyrone fails to add to 3. In either toluene or THF (used as solvent in the reaction with 1) starting materials are returned unchanged. In comparison, ethylene glycol intercepts substrates $\mathbf{3 b}$ and $\mathbf{3 c}$ to give products whose structures have yet to be resolved. ${ }^{19}$

One must ask why the regioselectivity exhibited by $\mathbf{3}$ and $\mathbf{4}$ is so different. Unfortunately FMO analysis ${ }^{20}$ cannot rationalize the experimental findings as the HOMO and LUMO of both 3 and 4 are concentrated at the exocyclic bond. To gain some insight into the different regioselectivity, the interaction of furan and DPIBF with the unknown parent methylidene compounds $\mathbf{3 a}$ and $\mathbf{4 a}$ as well the diphenyl derivatives $\mathbf{3 b}$ and $\mathbf{4 b}$ actually employed in the study have been examined using ab initio and semiempirical PM3 methods. 


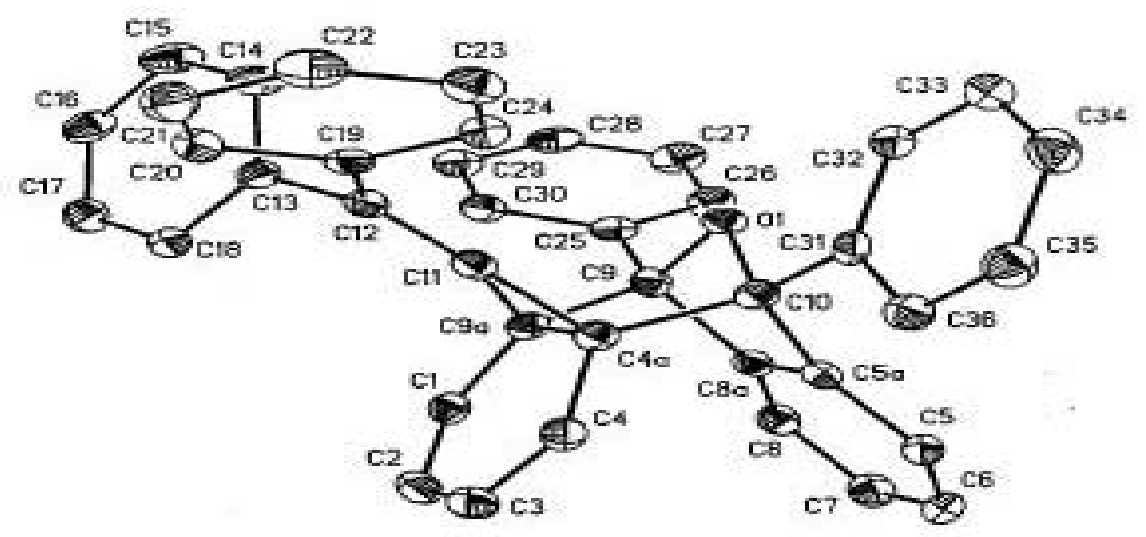

Figure 2. ORTEP diagram of the cation of $\mathbf{1 9 b}$ with crystallographic numbering.

\section{Theoretical Study}

The cycloaddition reactions of the unknown parent cycloproparene olefins 3a and 4a with furan have been studied at the ab initio MP2/6-31G(d)// HF/6-31G(d) (i.e. MP2/6-31G(d) single point energy calculations at the $\mathrm{HF} / 6-31 \mathrm{G}(\mathrm{d})$ optimised geometries) level of theory using the programs Gausian $92^{21}$ and Spartan 3.1. ${ }^{22}$ Vibrational frequencies were computed for all structures at the $\mathrm{HF} / 6-31 \mathrm{G}(\mathrm{d})$ level of theory in order to characterise them as minima (no imaginary frequencies) or transition state,TS (one imaginary frequency). Zero-point energies (ZPEs) were also calculated at $\mathrm{HF} / 6-31 \mathrm{G}(\mathrm{d})$. All ab initio energies reported in the discussion are calculated (unless stated otherwise) at the MP2/6-31G(d)//HF/6-31G(d) level and include unscaled ZPEs. 
Of the possible [4 +2] cycloadditions of 3a with furan the calculations predict that the transition states for exo and endo addition to the bridge bond and addition to the exocyclic double bond have essentially the same activation energy $\left(+18.7,+18.4\right.$ and $+18.2 \mathrm{kcal} \mathrm{mol}^{-1}$, respectively). No kinetic preference can be expected and the thermodynamically more stable product will result not from addition to the bridge, but to the exocyclic double bond to give product analogous to $\mathbf{1 0}$ (the corresponding reaction energies $(\Delta H r x n)$ are: $-11.8,-6.2$ and -20.4 $\mathrm{kcal} \mathrm{mol}^{-1}$, respectively). Of the two modes of addition to the bridge endo addition is predicted to give (on the basis of thermodynamics) the furan analogue of 19a in which the oxygen atom and the exocyclic double bond are syn ( $\Delta H \mathrm{rxn}$ : endo, -11.8; exo, $-6.2 \mathrm{kcal} \mathrm{mol}^{-1}$ ). It is clear that the calculations do not replicate the experimental observations in which 19b,c are isolated from $3 \mathbf{b , c}$ with DPIBF (Scheme 5). In contrast to this, the cyclopropanaphthalene analogue 4a shows a clear kinetic regioselectivity for furan addition to the exocyclic double bond $[\Delta \Delta E \mathrm{~A}$ (the difference in activation energies) is -14.2 and $\Delta \Delta H r x n-19.6 \mathrm{kcal} \mathrm{mol}^{-1}$, respectively] as is observed for the substituted substrates employed. The calculation also show that exo/endo additions to the bridge have the same activation energy $\left(\Delta E \mathrm{~A}+29.4\right.$ and $\left.+29.0 \mathrm{kcal} \mathrm{mol}^{-1}\right)$ but endo addition is again thermodynamically favoured, this time by $5.4 \mathrm{kcal} \mathrm{mol}^{-1}$.

Of course the substrates employed in the experimental study reflect the alkylidenecycloproparenes available and these carry bulky substituents. The size of the molecules involved has restricted further examination to the semiempirical PM3 level. The reactions of 3a and 4a with furan at the PM3 level are in qualitative agreement with the ab initio results. Regioselectivity for the exocyclic double bond is found for both cycloproparenes but for 3a there is only a $2 \mathrm{kcal} \mathrm{mol}^{-1}$ energy difference ( $\Delta$ Hrxn endo/exo/exocyclic: $-12.8 /-12.1 /-14.8$ $\left.\mathrm{kcal} \mathrm{mol}^{-1}\right)$; for 4a there is a clear reaction energy preference $\left(\Delta \Delta H \mathrm{rxn}-14.8 \mathrm{kcal} \mathrm{mol}^{-1} ; \Delta H \mathrm{rxn}\right.$ endo/exo/exocyclic: $-0.1 /-0.3 /-15.1 \mathrm{kcal} \mathrm{mol}^{-1}$ ). Next we assessed the influence of substituents on the methylidenecycloproparene by examining the diphenyl substituted substrates $\mathbf{3 b}$ and $\mathbf{4} \mathbf{b}$ in Diels-Alder reactions with furan; the regioselectivity is now changed from exocyclic to bridge addition ( $\Delta$ Hrxn 3b: endo/exo/exocyclic -12.4/-11.9/+2.8; 4b: endo/exo/exocyclic $-0.6 /-0.1 /+2.5$ $\mathrm{kcal} \mathrm{mol}^{-1}$ ). In contrast, reaction of DPIBF with the unsubstituted parents 3a and 4a provides data in agreement with the experimental observation. Thus benzenoid 3a gives regioselective endo addition of DPIBF to the bridge according to the calculations with a preference of $1.6 \mathrm{kcal}$ $\mathrm{mol}^{-1}$ ( $\Delta$ Hrxn endo/exo/exocyclic: -20.6/-17.5/-19.0 $\mathrm{kcal} \mathrm{mol}^{-1}$ ). In contrast, naphthalene 4a has a clear preference for the exocyclic double bond by some $12.1 \mathrm{kcal} \mathrm{mol}^{-1}(\Delta H \mathrm{Hrn}$ endo/exo/exocyclic: -8.8/-5.8/-20.9 $\mathrm{kcal} \mathrm{mol}^{-1}$ ). 
The dramatic changes calculated with substituent incorporation on one reactant are mirrored when the PM3 method is applied to the actual substrates employed, viz. the diphenyl derivatives $\mathbf{3 b}$ and $\mathbf{4 b}$ with DPIBF. In the case of $\mathbf{3 b}$ marked preference is for bridge addition ( $\triangle H \mathrm{Hxn}$ endo/exo/exocyclic: $-19.8 /-18.0 /+4.2 \mathrm{kcal} \mathrm{mol}^{-1}$ ) and the endo transition states that are involved. We conclude, therefore, that the observed experimental regioselectivity in these reactions is governed by a combination of steric effects and solvent influences that dictate the precise transition structure involved. This failure of theory is rather unexpected (and disappointing) in view of the general success of ab initio calculations to reproduce reliably the transition state energies (and thus relative reactivity, regioselectivity, etc.) of a wide variety of Diels-Alder and other cycloaddition reactions. ${ }^{23}$

It will be interesting to study if density functional theory (DFT) calculations will provide better agreement with experiment.

\section{X-ray Crystallographic Analyses}

In order to provide unambiguous proof of the formation of the naphthyliodonium triflates 18, the crystal structure of 18d has been determined. A suitable crystal was obtained by slow crystallization from a saturated $\mathrm{MeCN} / \mathrm{C}_{6} \mathrm{H}_{14}$ solution and the X-ray determination performed using a CAD4 four circle diffractometer with Mo-Ka radiation. Relevant data pertaining to the analysis are in Table 1, an elipsoid plot for the cationic component of 18d (crystallographic numbering appended) is shown in Figure 1, and selected bond lengths and angles appear in Table 2. 
Table 1. Experimental data for structure analyses of $\mathbf{1 8 d}$ and $19 \mathbf{b}^{\mathrm{a}}$

\begin{tabular}{ccc}
\hline & $\mathbf{1 8 d}$ & $\mathbf{1 9 b}$ \\
\hline Crystal size $\left(\mathrm{mm}_{3}\right)$ & $0.40 \times 0.35 \times 0.23$ & $0.25 \times 0.35 \times 0.30$ \\
Chemical formula & $\mathrm{C}_{33} \mathrm{H}_{20} \mathrm{O} 4 \mathrm{~F} 9 \mathrm{SI}$ & $\mathrm{C} 40 \mathrm{H} 28 \mathrm{O}$ \\
Temperature $(\mathrm{K})$ & ambient & 120 \\
Space group & & - \\
Space group no. & $P 2(1) / \mathrm{c}$ & $P 1$ \\
$Z$ & 14 & 2 \\
$a(\AA)$ & 4 & 2 \\
$b(\AA)$ & $12.046(1)$ & $9.557(2)$ \\
$c(\AA)$ & $18.822(2)$ & $10.111(3)$ \\
$\alpha(\zeta)$ & $15.416(2)$ & $14.752(4)$ \\
$\beta(\zeta)$ & $90.00(0)$ & $84.73(2)$ \\
$\gamma(\zeta)$ & $112.055(3)$ & $82.55(2)$ \\
$V(\AA)$ & $90.00(0)$ & $88.08(2)$ \\
$\mathrm{d}_{\text {calc. }}\left(\mathrm{g} \mathrm{cm}^{-3}\right)$ & 3239.38 & $1407.2(6)$ \\
$\mu\left(\mathrm{mm}^{-1}\right)$ & 1.667 & 1.238 \\
$2 \Theta$ range $\left({ }^{\circ}\right)$ & $2 \leq 2 \Theta \leq 48$ & 0.07 \\
Unique reflections $_{\text {Observed reflections }}$ & 5663 & $3 \leq 2 \Theta \leq 45$ \\
$\mathrm{~F}_{\mathrm{O} \geq} 4 \sigma(\mathrm{F})$ & 3699 & 4944 \\
$R, R_{\mathrm{w}}$ & $0.0492,0.0515$ & $0.0518,0.0516$ \\
\hline
\end{tabular}

${ }^{a}$ Deposited with the Cambridge Crystallographic Data Centre.as: 18d: CCDC 160279; 19b CCDC 160957. 
The structure is confirmed as 1-(2'-naphthyl-3'-phenyliodonium)-2,2-bis(3"trifluoromethylphenyl)ethanone triflate (18d). In similar vein, a crystal of 19b was obtained (acetonitrile/hexane) and the X-ray determination performed using a Nicolet $\mathrm{R} 3 \mathrm{~m} / \mathrm{V}$ diffractometer with Mo-K $\alpha$ radiation. Relevant data pertaining to this analysis appear in Tables 1 and 3, and the elipsoid plot with numbering scheme is Figure 2. The compound is confirmed as [4a $\alpha, 9 \alpha, 9 \mathrm{a} \alpha, 10 \alpha]-9,10$-diphenyl-11-diphenylmethylidene-4a,9,9a,10-tetrahydro-9,10-epoxy4a,9a,-methanoanthracene (19b).

Table 2. Selected bond lengths $(\AA)$ and angles $\left(^{\circ}\right)$ for $\mathbf{1 8 d}^{a}$

\begin{tabular}{cccc}
\hline \multicolumn{2}{c}{ Bond Length } & \multicolumn{2}{c}{ Bond Angle } \\
\hline $\mathrm{C} 1-\mathrm{C} 2$ & $1.363(4)$ & $\mathrm{C} 1-\mathrm{C} 10-\mathrm{C} 9$ & $120.3(3)$ \\
$\mathrm{C} 1-\mathrm{C} 10$ & $1.427(4)$ & $\mathrm{C} 1-\mathrm{I}-\mathrm{C} 27$ & $94.8(1)$ \\
$\mathrm{C} 2-\mathrm{C} 3$ & $1.417(4)$ & $\mathrm{I}-\mathrm{C} 1-\mathrm{C} 2$ & $118.8(2)$ \\
$\mathrm{C} 3-\mathrm{C} 8$ & $1.412(5)$ & $\mathrm{I}-\mathrm{C} 1-\mathrm{C} 10$ & $118.4(2)$ \\
$\mathrm{C} 8-\mathrm{C} 9$ & $1.417(4)$ & $\mathrm{C} 2-\mathrm{C} 1-\mathrm{C} 10$ & $122.7(3)$ \\
$\mathrm{C} 9-\mathrm{C} 10$ & $1.383(4)$ & $\mathrm{C} 1-\mathrm{C} 2-\mathrm{C} 3$ & $120.0(3)$ \\
$\mathrm{C} 10-\mathrm{C} 11$ & $1.472(5)$ & $\mathrm{C} 2-\mathrm{C} 3-\mathrm{C} 8$ & $118.7(3)$ \\
$\mathrm{C} 11-\mathrm{C} 12$ & $1.521(5)$ & $\mathrm{C} 3-\mathrm{C} 8-\mathrm{C} 9$ & $119.8(3)$ \\
$\mathrm{C} 11-\mathrm{O} 1$ & $1.232(4)$ & $\mathrm{C} 8-\mathrm{C} 9-\mathrm{C} 10$ & $121.1(3)$ \\
$\mathrm{C} 1-\mathrm{I}$ & $2.131(3)$ & $\mathrm{C} 10-\mathrm{C} 11-\mathrm{C} 12$ & $119.8(3)$ \\
$\mathrm{I}-\mathrm{C} 27$ & $2.094(4)$ & $\mathrm{O} 1-\mathrm{C} 11-\mathrm{C} 10$ & $119.0(3)$ \\
& & $\mathrm{O} 1-\mathrm{C} 11-\mathrm{C} 12$ & $121.1(3)$ \\
\hline
\end{tabular}

${ }^{a}$ Numbers in parenthesis are the estimated standard deviations in the least significant digit. 
Table 3. Selected bond lengths $(\AA)$ and angles $\left({ }^{\circ}\right)$ for $\mathbf{1 9 b}^{a}$

\begin{tabular}{cccc}
\hline \multicolumn{2}{c}{ Bond Length } & \multicolumn{2}{c}{ Bond Angle } \\
\hline $\mathrm{C} 1-\mathrm{C} 2$ & $1.344(4)$ & $\mathrm{C} 9-\mathrm{O} 1-\mathrm{C} 10$ & $99.3(2)$ \\
$\mathrm{C} 2-\mathrm{C} 3$ & $1.460(4)$ & $\mathrm{C} 2-\mathrm{C} 1-\mathrm{C} 9 \mathrm{a}$ & $120.6(2)$ \\
$\mathrm{C} 3-\mathrm{C} 4$ & $1.342(4)$ & $\mathrm{C} 1-\mathrm{C} 2-\mathrm{C} 3$ & $122.1(2)$ \\
$\mathrm{C} 4-\mathrm{C} 4 \mathrm{a}$ & $1.487(4)$ & $\mathrm{C} 2-\mathrm{C} 3-\mathrm{C} 4$ & $123.3(2)$ \\
$\mathrm{C} 4 \mathrm{a}-\mathrm{C} 9 \mathrm{a}$ & $1.584(3)$ & $\mathrm{C} 3-\mathrm{C} 4-\mathrm{C} 4 \mathrm{a}$ & $120.6(2)$ \\
$\mathrm{C} 1-\mathrm{C} 9 \mathrm{a}$ & $1.485(3)$ & $\mathrm{C} 4-\mathrm{C} 4 \mathrm{a}-\mathrm{C} 9 \mathrm{a}$ & $116.0(2)$ \\
$\mathrm{C} 4 \mathrm{a}-\mathrm{C} 10$ & $1.576(3)$ & $\mathrm{C} 1-\mathrm{C} 9 \mathrm{a}-\mathrm{C} 4 \mathrm{a}$ & $116.9(2)$ \\
$\mathrm{C} 4 \mathrm{a}-\mathrm{C} 11$ & $1.475(4)$ & $\mathrm{C} 9 \mathrm{a}-\mathrm{C} 4 \mathrm{a}-\mathrm{C} 11$ & $57.6(2)$ \\
$\mathrm{C} 9 \mathrm{a}-\mathrm{C} 11$ & $1.477(3)$ & $\mathrm{C} 4 \mathrm{a}-\mathrm{C} 9 \mathrm{a}-\mathrm{C} 11$ & $57.5(2)$ \\
$\mathrm{C} 9-\mathrm{C} 9 \mathrm{a}$ & $1.553(3)$ & $\mathrm{C} 4 \mathrm{a}-\mathrm{C} 11-\mathrm{C} 9 \mathrm{a}$ & $64.9(2)$ \\
$\mathrm{C} 11-\mathrm{C} 12$ & $1.330(4)$ & $\mathrm{C} 4 \mathrm{a}-\mathrm{C} 11-\mathrm{C} 12$ & $148.6(2)$ \\
& & $\mathrm{C} 9 \mathrm{a}-\mathrm{C} 11-\mathrm{C} 12$ & $145.4(2)$ \\
\hline
\end{tabular}

${ }^{a}$ Numbers in parenthesis are the estimated standard deviations in the least significant digit. 


\section{Experimental Section}

General Procedures: These have appeared previously. ${ }^{7}$ NMR spectra were recorded at $300\left({ }^{1} \mathrm{H}\right)$ and $75 \mathrm{MHz}\left({ }^{13} \mathrm{C}\right)$ in (D)chloroform solutions for 11, 13 and 19, and in $\mathrm{CD} 3 \mathrm{CN}$ for $\mathbf{1 8 b}-\mathbf{d}$.

\section{Cycloaddition reactions of 3 and 4 with DPIBF}

To a solution of $\mathbf{3}$ or $\mathbf{4}$ in dry, degassed, ethylene glycol under nitrogen was added diphenylisobenzofuran (DPIBF, 2.0 mol. equiv.). The mixture was heated to $110^{\circ} \mathrm{C}$ for ca. $7 \mathrm{~h}$ for 4 , but $120^{\circ} \mathrm{C}$ for $24 \mathrm{~h}$ for 3 . The mixture was cooled and the solvent removed in vacuum. The crude product was purified by flash column chromatography over silica gel. Hexane/ethyl acetate (9:1) elution gave the cyclobutarenes 11 from $\mathbf{4}$. The products from 3 were obtained from light petroleum elution (which displaced unchanged DPIBF) followed by flushing the column with $\mathrm{CH}_{2} \mathrm{Cl}_{2}$.

\section{A. Cyclobutarene (11b). $4 b^{6}$}

(152 $\mathrm{mg}, 0.5 \mathrm{mmol})$ and DPIBF $(270 \mathrm{mg}, 1.0 \mathrm{mmol})$ gave $11 \mathrm{~b}(154 \mathrm{mg}, 55 \%)$ as a pale yellow solid, mp 124-125 ${ }^{\circ} \mathrm{C}$ : IR $\left(\mathrm{CCl}_{4}\right)$ 805, 937, 1026, 1074, 1153, 1180, 1194, 1278, 1315, 1448, 1490, 1596, 1659, $1665(\mathrm{C}=\mathrm{O}), 1738,3026,3061 \mathrm{~cm}^{-1} ;{ }^{1} \mathrm{H}$ NMR $\delta$ 7.1-7.8 (complex m); ${ }^{13} \mathrm{C}$ NMR $\delta 76.1$ (cyclobutyl), 120.3, 126.6, 126.9, 128.3, 128.7, 129.4, 130.0, 132.8, 138.2, 140.2, 150.3, 163.1, $198.2(\mathrm{C}=\mathrm{O})$; MS m/z $574\left(\mathrm{M}^{+}\right)$. Anal. Calcd for $\mathrm{C}_{44} \mathrm{H}_{30} \mathrm{O}: \mathrm{C}, 91.95 ; \mathrm{H}, 5.26$. Found: C, 92.02; H, 5.24.

\section{B. Cyclobutarene (11c). $4 c^{11}$}

(182 $\mathrm{mg}, 0.5 \mathrm{mmol})$ and DPIBF (270 mg, $1.0 \mathrm{mmol})$ gave 11c $(101 \mathrm{mg}, 32 \%)$ as a pale orange solid, mp 103-104 ${ }^{\circ} \mathrm{C}$ : IR $\left(\mathrm{CCl}_{4}\right)$ 874, 910, 1023, 1067, 1081, 1153, 1189, 1222, 1271, 1392, 1397, 1460, 1590, 1618, $1670(\mathrm{C}=\mathrm{O}), 1742,2925,2960,3028 \mathrm{~cm}^{-1} ;{ }^{1} \mathrm{H}$ NMR $\delta 3.62$ (s, 2xOMe), 7.2-7.3 (m, 7H), 7.3-7.5 (m, 10H), 7.5-7.8 (m, 11H); ${ }^{13} \mathrm{C}$ NMR $\delta 53.4(\mathrm{OMe}), 77.2$ (cyclobutyl), $123.1,125.1,125.3,125.6,125.9,126.3,128.2$, 129.0, 129.3, 130.4, 134.6, 149.1, 161.2, 196.3 $(\mathrm{C}=\mathrm{O})$; MS m/z $634\left(\mathrm{M}^{+}\right)$. Anal. Calcd for $\mathrm{C}_{46} \mathrm{H}_{34} \mathrm{O}_{3}$ : C, 87.04; H, 5.40. Found: C, 86.97; H, 5.46 .

\section{Cyclobutarene (11d). $4 d^{12}$}

(220 mg, $0.5 \mathrm{mmol}$ ) and DPIBF (270 mg, $1.0 \mathrm{mmol})$ gave 11d (150 mg, 42\%) as an orange solid, mp 98-99 ${ }^{\circ}$ : IR $\left(\mathrm{CCl}_{4}\right) 810,839,864,886,900$,

979, 1035, 1076, 1133, 1192, 1247, 1365, 1392, 1434, 1463, 1478, $1661(\mathrm{C}=\mathrm{O}), 1737,2869$, 
2902, 2935, 2961, 2968, $\mathrm{cm}^{-1} ;{ }^{1} \mathrm{H}$ NMR $\delta$ 7.1-8.0 (complex m); ${ }^{13} \mathrm{C}$ NMR $\delta 79.3$ (cyclobutyl), 126.4, 128.0, 129.8, 130.0, 131.3, 131.9, 133.2, 134.1, 137.4, 137.9, 138.2, 151.3, 159.4, 199.1 $(\mathrm{C}=\mathrm{O}) ;{ }^{19} \mathrm{~F}$ NMR $(\mathrm{CD} 3 \mathrm{CN}) \delta$-81.5; MS m/z $710\left(\mathrm{M}^{+}\right)$. Anal. Calcd for $\mathrm{C}_{46} \mathrm{H}_{28} \mathrm{OF}_{6}: \mathrm{C}, 77.74 ; \mathrm{H}$, 3.97. Found: $\mathrm{C}, 77.83 ; \mathrm{H}, 4.10$.

\section{Norcaradiene (19b). $3 b^{6}$}

(100 mg, $0.39 \mathrm{mmol})$ and DPIBF $(212 \mathrm{mg}, 0.79 \mathrm{mmol})$ gave firstly unchanged dpibf (58 $\mathrm{mg}$, 27\%) then (with $\mathrm{CH}_{2} \mathrm{Cl}_{2}$ ) 19b as a green oil which crystallized (light petroleum) (97 $\mathrm{mg}, 48 \%$ ), mp 242-244 ${ }^{\circ} \mathrm{C}$ : IR 3048, 3032, 3005, 1956, 1885, 1813, 1601, 1495, 1456, 1444, 1375, 1298, 1155, 1074, 1011, 989; ${ }^{1} \mathrm{H}$ NMR $\delta 5.67(\mathrm{dd}, J$ 2.3, $7.5 \mathrm{~Hz}, 2 \mathrm{H}) ; 6.11(\mathrm{dd}, J$ 2.3, 7.5, 2H); 7.05$7.60(\mathrm{~m}, 24 \mathrm{H}) ;{ }^{13} \mathrm{C}$ NMR $\delta 45.42 \mathrm{C} 4 \mathrm{a}(9 \mathrm{a}) ; 91.80 \mathrm{C} 9(10) ; 120.75,122.31,122.34,126.01$, 127.26, 127.80, 128.39, 128.45, 128.51 all $\mathrm{CH}$; 130.87, 134.50, 135.18, 140.08, 149.92 all C; MS m/z 525, 524 (10.0, 23.4\%; M); 420, 419 (5.7, 15.5; M-PhCO); 341, 339 (17.3, 16.5), 271, 270 (22.9, 100; dpibf); 254 (16.0, M-dpibf), 252 (21.1, M-dpibf-H2), 165 (30.4), 105 (31.3, PhCO), 77 (32.9). Anal. Calcd for $\mathrm{C}_{40} \mathrm{H}_{28} \mathrm{O}$ : C, 91.56; H 5.38. Found: C, 91.48; H 5.53. The product is confirmed as 19b from X-ray crystal structure analysis.

With toluene as solvent the yield of $19 b$ was $41 \%$ and the recovered DPIBF was $44 \%$.

\section{E. Norcaradiene (19c). $3 c^{11}$}

(100 mg, $0.32 \mathrm{mmol}$ ) and DPIBF (172 mg, $0.64 \mathrm{mmol}$ ) gave unchanged DPIBF (103 mg, 60\%) followed by $19 \mathrm{c}(50 \mathrm{mg}, 27 \%)$ as pale brown needles $\left(\mathrm{CH}_{2} \mathrm{Cl}_{2} /\right.$ light petroleum, 1:1), mp 223.5$225^{\circ} \mathrm{C}$ : IR 3036, 2963, 2932, 2834, 1605, 1508, 1447, 1283, 1246, 1171, 1028, 835, 745, 704, 693, 552; ${ }^{1} \mathrm{H}$ NMR $\delta 3.80\left(\mathrm{~s}, 2 \mathrm{xOCH}_{3}\right) ; 5.64(\mathrm{dd}, J 2.2,7.5 \mathrm{~Hz}, 2 \mathrm{H}) ; 6.11(\mathrm{dd}, J 2.2,7.5 \mathrm{~Hz}, 2 \mathrm{H})$; $6.69\left(\mathrm{~d}, J\right.$ 8.6, 4H; 7.05-7.12, m, 8H); 7.29-7.60 (m, 10H); ${ }^{13} \mathrm{C} \mathrm{NMR} \delta 45.5, \mathrm{C} 4 \mathrm{a}(9 \mathrm{a}) ; 55.3$, $2 \mathrm{xOCH}_{3}, 91.7$, C9(10); 113.13, 120.7, 122.1, 122.6, 126.0, 128.4, 128.5, 130.6 all CH; 127.9, 133.06, 133.6, 135.3, 150.0, 159.0 all C; MS m/z 585, 584 (6.0, 13.4\%; M); 480, 479 (3.7, 9.9; M-PhCO); 315, 314 (24.8, 100; M-dpibf); 300, 299 (12.7, 46.4; M-dpibf- $\left.\mathrm{CH}_{3}\right) ; 271,270$ (17.9, 68.1; dpibf); 105 (20.1, $\mathrm{PhCO}$ ), 77 (25.3). Anal. Calcd for $\mathrm{C}_{42} \mathrm{H}_{32} \mathrm{O}_{3}: \mathrm{C}, 86.26$; H, 5.52. Found: C, 86.04; H, 5.44 .

With toluene as solvent the yield of 19c was $18 \%$ and the recovered DPIBF was $77 \%$. 


\section{Cycloaddition reactions of 3 and 4 with a -pyrone}

To a solution of $\mathbf{3}$ or $\mathbf{4}$ in dry, degassed, ethylene glycol under nitrogen was added excess of $\alpha$ pyrone. For 4 the mixture was heated to $110^{\circ} \mathrm{C}$ for ca. $12 \mathrm{~h}$ while $120^{\circ} \mathrm{C}$ and $24 \mathrm{~h}$ were employed for 3. After cooling, the solvent was removed under reduced pressure and the crude product purified. The indanone product $\mathbf{1 3}$ from $\mathbf{4}$ was obtained from flash column chromatography (silica gel, 9:1 hexane/ethyl acetate elution) while for 3 column chromatography employed ethyl acetate/light petroleum (1:7) elution.

\section{A. Benz[f]indanone (13b). $4 b^{6}$}

(100mg, $0.33 \mathrm{mmol}$ ) and $\alpha$-pyrone $(53 \mu \mathrm{l}, 0.66 \mathrm{mmol})$ gave 13b $(66 \mathrm{mg}, 50 \%)$ as a brown solid, mp 92-93 ${ }^{\circ} \mathrm{C}$ : IR $\left(\mathrm{CCl}_{4}\right) 880,925,1087,1134,1175,1189,1265,1343,1425,1487,1597,1618$, $1640(\mathrm{C}=\mathrm{O}), 1715$ (CHO), 1775, 2850, 2965, 3025, $3088 \mathrm{~cm}^{-1} ;{ }^{1} \mathrm{H}$ NMR $\delta 3.10(\mathrm{~d}, 1 \mathrm{H}$, cyclopentyl), 5.81 (d, 1H, vinyl), 6.32 (dd, 1H vinyl), 6.9-7.8 (complex m, 14H), 7.85 (bs, 2H), 9.48 (s, CHO); ${ }^{13} \mathrm{C}$ NMR $\delta 76.6$ (cyclopentyl) 122.1, 123.1, 123.2, 123.5, 123.7, 124.2, 124.6, 124.8, 125.3, 127.2, 129.2, 130.0, 131.3, $161.3(\mathrm{C}=\mathrm{O}), 193.0(\mathrm{CHO})$; MS m/z $400\left(\mathrm{M}^{+}\right)$. Anal. Calcd for $\mathrm{C}_{29} \mathrm{H}_{20} \mathrm{O}_{2}$ : C, 82.16; H, 6.89. Found: C, 82.28; H, 6.80.

B. Benz[f]indanone (13c). $4 c^{11}(100 \mathrm{mg}, 0.27 \mathrm{mmol})$ and $\alpha$-pyrone $(44 \mu \mathrm{l}, 0.55 \mathrm{mmol})$ gave 13c (31.2 mg, 25\%) as a brown solid, $\mathrm{mp} 100-101^{\circ} \mathrm{C}$ : IR $\left(\mathrm{CCl}_{4}\right) 801,834,1008,1020,1031,1113$, $1160,1178,1253,1287,1461,1510,1602,1626,1671,1720,1773,2838,2928,2962,3054 \mathrm{~cm}^{-}$ ${ }^{1} ;{ }^{1} \mathrm{H}$ NMR $\delta 3.05$ (d, 1H, cyclopentyl), 3.51 (s, 2xOMe), 5.89 (d, 1H, vinyl), 5.98 (dd, 1H, vinyl), 6.7-8.0 (m, 14H), $9.53(\mathrm{~s}, \mathrm{CHO}) ;{ }^{13} \mathrm{C}$ NMR $\delta 51.4$ (OMe), 74.6 (cyclopentyl), 120.9, $121.3,122.3,122.6,123.0,123.7,124.0,124.3,125.3,125.5,125.8,126.2,127.1,164.1(\mathrm{C}=\mathrm{O})$, 189.2 (CHO); MS m/z (444, $\mathrm{M}^{+}$). Anal. Calcd for $\mathrm{C}_{31} \mathrm{H}_{24} \mathrm{O}_{4}$ : C, 80.85; H, 5.25. Found: C, 80.72; H, 5.31 .

\section{Benz[f]indanone (13d). $4 d^{12}$}

(100 mg, $0.23 \mathrm{mmol})$ and $\alpha$-pyrone $(40 \mu \mathrm{l}, 0.50 \mathrm{mmol})$ gave 13d $(24.0 \mathrm{mg}, 16 \%)$ as a deep orange solid, mp $87-88^{\circ} \mathrm{C}$ : IR $\left(\mathrm{CCl}_{4}\right) 799,829,897,1076,1088,1121,1179,1313,1324,1445$, 1540, 1612, 1632, 1718, 1777, 2888, 2934, 3055, $3074 \mathrm{~cm}^{-1} ;{ }^{1} \mathrm{H}$ NMR $\delta 3.13(\mathrm{~d}, 1 \mathrm{H}$, cyclopentyl), 6.17 (d, 1H vinyl), 6.32 (dd, 1H, vinyl), 7.2-7.9 (m, 12H), 8.43 (bs, 2H), 9.71 (s, $\mathrm{CHO}) ;{ }^{13} \mathrm{C}$ NMR $\delta 78.3$ (cyclopentyl), 123.2, 123.5, 123.9, 124.6, 124.7, 124.9, 125.5, 125.8, 126.6, 127.8, 129.5, 132.3, $159.4(\mathrm{C}=\mathrm{O}), 197.3(\mathrm{CHO}) ;{ }^{19} \mathrm{~F}$ NMR $\left(\mathrm{CD}_{3} \mathrm{CN}\right) \delta-80.9$; $\mathrm{MS} \mathrm{m} / \mathrm{z} 536$ $\left(\mathrm{M}^{+}\right)$. Anal. Calcd for $\mathrm{C}_{31} \mathrm{H}_{18} \mathrm{O}_{2} \mathrm{~F}_{6}$ : C, 69.41; H, 3.38. Found: C, 69.15; H, 3.45. 
D. $3 \mathbf{b}^{6}(70 \mathrm{mg}, 0.28 \mathrm{mmol})$ and $\alpha$-pyrone $(100 \mathrm{mg}, 1.1 \mathrm{mmol})$ provided a pale green-yellow oil (73.1 mg, 92\%) which has eluded identification.

With either refluxing toluene for $48 \mathrm{~h}$ or THF at $70^{\circ} \mathrm{C}$ for 5 days only unchanged starting material were recovered.

E. $3 c^{11}(100 \mathrm{mg}, 0.32 \mathrm{mmol})$ and $\alpha$-pyrone $(61 \mathrm{mg}, 0.64 \mathrm{mmol})$ provided no product until the column was flushed with methanol. A white amorphous solid (53.1 mg, 44\%) that has eluded identification was obtained.

With either refluxing toluene for $24 \mathrm{~h}$ or THF at $70^{\circ} \mathrm{C}$ for 5 days only unchanged starting material were recovered.

\section{Cycloaddition reactions of 4 with acetylenic bis-iodonium triflate (14).}

To a solution of 4 in dry, degassed acetonitrile $(10 \mathrm{~mL})$ under nitrogen was added the bisiodonium salt $14^{18}$ (1.0 mol. equiv.) and the mixture was stirred at RT for $7 \mathrm{~h}$. The solvent was removed in vacuum and the crude product recrystallized $\left(\mathrm{CH}_{2} \mathrm{Cl}_{2} / \mathrm{C}_{6} \mathrm{H}_{14}\right)$ to give cycloadduct 18 . All NMR data recorded below are for $\mathrm{CD}_{3} \mathrm{CN}$ solutions.

\section{A. Naphthyl iodonium salt (18b). $4 b^{6}$}

(100 mg, $0.33 \mathrm{mmol})$ and $14^{18}(240 \mathrm{mg}, 0.33 \mathrm{mmol})$ gave $\mathbf{1 8 b}(119 \mathrm{mg}, 53 \%)$ as a white solid, mp $125^{\circ} \mathrm{C}(\mathrm{dec})$ : IR $\left(\mathrm{CCl}_{4}\right)$ 946, 1028, 1069, 1083, 1121, 1194, 1245 (OTf), 1260, 1442, 1493, 1542, 1598, $1651(\mathrm{C}=\mathrm{O}), 2874,2935,2962,3028,3054 \mathrm{~cm}^{-1} ;{ }^{1} \mathrm{H}$ NMR $\delta 2.31$, (s, >CH-), 6.83 (bs, 2H), 7.0-7.5 (m, 11H), 7.59 (bs, 2H), 8.0-8.15 (m, 4H), 8.25-8.45 (m, 2h); ${ }^{13} \mathrm{C}$ NMR $\delta 52.4$ (CH), 122.3, 123.9, 125.8, 127.1, 128.3, 128.7, 129.8, 130.4, 130.9, 131.7, 133.2, 134.5, 137.2, $195.2(\mathrm{C}=\mathrm{O}) ;{ }^{19} \mathrm{~F}$ NMR $\delta$-78.7; MS (FAB) m/z $525\left(\mathrm{M}^{+}\right.$-OTf). Anal. Calcd for $\mathrm{C}_{31} \mathrm{H}_{22} \mathrm{O}_{4} \mathrm{SF}_{3} \mathrm{I}$ : C, 55.20; H, 3.29. Found: C, 54.89; H, 3.41.

\section{B. Naphthyl iodonium salt (18c). $4 \mathrm{c}^{11}$}

$(100 \mathrm{mg}, 0.27 \mathrm{mmol})$ and $14^{18}(200 \mathrm{mg}, 0.27 \mathrm{mmol})$ gave $\mathbf{1 8 c}(85 \mathrm{mg}, 39 \%)$ as a pale brown solid, mp 97-99 ${ }^{\circ} \mathrm{C}$ (dec): IR $\left(\mathrm{CCl}_{4}\right)$ 828, 1032, 1123, 1177, 1245 (OTf), 1286, 1440, 1463, 1510, 1581, 1607, 1624, $1658(\mathrm{C}=\mathrm{O}), 2836,2908,2932,2953,3000,3058 \mathrm{~cm}^{-1} ;{ }^{1} \mathrm{H}$ NMR $\delta 2.34$, (s, $1 \mathrm{H}, \mathrm{CH}), 3.84$ (s, 2xOMe), 7.3-8.5 (complex m, 19H); ${ }^{13} \mathrm{C}$ NMR $\delta 54.5(\mathrm{CH}) 121.5,122.5$, $122.9,124.1,124.8,126.1,126.3,126.8,128.2,128.6,129.4,130.2,131.4,134.1,135.3,198.4$ $(\mathrm{C}=\mathrm{O}) ;{ }^{19} \mathrm{~F}$ NMR $\delta$-78.9; MS (FAB) $\mathrm{m} / \mathrm{z} 585\left(\mathrm{M}^{+}\right.$-OTf). Anal. Calcd for $\mathrm{C}_{33} \mathrm{H}_{26} \mathrm{O}_{6} \mathrm{SF}_{3} \mathrm{I}: \mathrm{C}$, 53.96; H, 3.57. Found: C, 53.45; H, 3.24. 


\section{Naphthyl iodonium salt (18d). $4 d^{12}$}

(100 $\mathrm{mg}, 0.23 \mathrm{mmol})$ and $\mathbf{1 4}^{18}(170 \mathrm{mg}, 0.23 \mathrm{mmol})$ gave $\mathbf{1 8 d}(112 \mathrm{mg}, 60 \%)$ as a white solid, mp $116^{\circ} \mathrm{C}$ (dec): IR $\left(\mathrm{CCl}_{4}\right)$ 891, 994, 1028, 1077, 1126, 1165, 1226, 1245 (OTf), 1258, 1281, 1330, 1446, 1578, 1617, $1645(\mathrm{C}=\mathrm{O}), 3063,3069 \mathrm{~cm}^{-1} ;{ }^{1} \mathrm{H}$ NMR $\delta 2.45$ (s, >CH-), 7.2-7.3 (m, $4 \mathrm{H}), 7.65-7.75(\mathrm{~m}, 4 \mathrm{H}), 7.9-8.3(\mathrm{~m}, 7 \mathrm{H}), 8.45-8.55(\mathrm{~m}, 4 \mathrm{H}) ;{ }^{13} \mathrm{C} \mathrm{NMR} \delta 57.3(\mathrm{CH}), 123.9,124.3$, $124.9,125.5,126.0,126.2,126.3,126.8,127.3,128.4,129.1,131.3,132.8,135.6,139.8,140.5$, $201.0(\mathrm{C}=\mathrm{O})$; ${ }^{19} \mathrm{~F}$ NMR $\delta$-78.5 (OTf), -82.1 $\left(\mathrm{CF}_{3}\right)$; MS (FAB) $\mathrm{m} / \mathrm{z} 661\left(\mathrm{M}^{+}-\mathrm{OTf}\right)$. Anal. Calcd for $\mathrm{C}_{33} \mathrm{H}_{20} \mathrm{O} 4 \mathrm{SF}_{9} \mathrm{I}: \mathrm{C}, 48.90 ; \mathrm{H}, 2.49$. Found: C, 48.13; H, 2.35.

\section{Supporting Information.}

Supplementary crystallographic data (excluding structure factors) have been deposited with the Cambridge Crystallographic data Centre as supplementary publications: CCDC 160279 (18d) and 160957 (19b). Copies of the data can be obtained free of charge on application to CCDC, 12 Union Rd., Cambridge, CB2 1EZ, UK (e-mail: deposit@ccdc.cam.ac.uk).

\section{Acknowledgements}

Financial support in Wellington from the former Internal Grants Committee of Victoria University, in Utah from the National Science Foundation (CHE9101767) and the donors of the Petroleum Research Fund (administered by the American Chemical Society), at Technion from the V.P.R. Fund for the Promotion of Research (partial support), and in Essen by the Deutsche Forschungsgemeinschaft and the Fonds der Chemischen Industrie is gratefully acknowledged. We are pleased to acknowledge generous support and computational time (to A.H.M.) at the Hochschulrechenzentrum Essen and the Regionales Rechenzentrum Köln.

\section{References and Notes}

1. Previous part: Halton, B.; Jones, C. S., Margetic, D. Tetrahedron 2001, 57, 3529.

2. (a) Halton, B. CYCLOPROPARENES In The Chemistry of the Cyclopropyl Group Rappoport, Z. Ed., Wiley: Chichester, 1995; 707. (b) Halton, B. Chem. Rev. 1989, 89, 116. (c) Müller, P. In Carbocyclic Three-Membered Ring Compounds de Meijere, A., Ed., 
Thieme: Stuttgart, 1997; Vol. E/17d. (d) Müller, P. In Advances in Theoretically Interesting Molecules Thummel, R. P., Ed., JAI Press: Greenwich CT, 1995; Vol. 3, 37.

3. (a) Eaborn, C.; Eidenschink, R.; Harris, S. J.; Walton, D. M. R. J. Organomet. Chem. 1977, 124, C27. (b) Eaborn, C.; Stamper, J. G. J. Organomet. Chem. 1980, 192, 155.

4. Halton, B.; Stang, P. J. Synlett 1997, 145.

5. Halton, B.; Jones, C. S.; Northcote, P. T.; Boese, R. Aust. J. Chem. 1999, 52, 285 and refs. cited.

6. Halton, B.; Randall, C. J.; Gainsford, G. J.; Stang, P. J. J. Am. Chem. Soc. 1986, 108, 5949.

7. (a) Bickers, P. T.; Halton, B.; Kay, A. J.; Northcote, P. T. Aust. J. Chem. 1999, 52, 647. (b) Halton, B.; Halton, B.; Cooney, M. J.; Boese, R.; Maulitz, A. H. J. Org. Chem. 1998, 63, 1583. (c) Halton, B.; Jones, C. S.; Kay, A. J.; Margetic, D.; Sretenovic, S. J. Chem. Soc., Perkin Trans. 1 2000, 2205.

8. Preliminary communications covering parts of this study have appeared: (a) Halton, B.; Kay, A. J.; McNichols, A. T.; Stang, P. J.; Boese, R.; Haumann, T.; Apeloig, Y.; Maulitz, A. H. Tetrahedron Lett. 1993, 34, 6151. (b) McNichols, A. T.; Stang, P. J.; Halton, B.; Kay, A. J. Tetrahedron Lett. 1993, 34, 3131.

9. (a) Laue, J.; Seitz, G.; Wassmuth, H. Z. Naturforsch. Teil B. 1996, 51, 348. (b) Ando, S.; Imamura, J.; Tajitsu, M.; Saito, K. Heterocycles 1998, 48, 1769. (c) Saito, K.; Ando, S.; Kondo, Y. Heterocycles 2000, 53, 2601.

10. (a) Brinker, U. H.; Wüster, H. Tetrahedron Lett. 1991, 32, 593. (b) Halton, B.; Russell, S. G. G. Aust. J. Chem. 1990, 43, 2099. (c) Saito, K.; Ishihara, H.; Kagabu, S. Bull. Soc. Chem. Jpn. 1987, 60, 4141.

11. Halton, B.; Buckland, S. J.; Lu, Q.; Mei, Q.; Stang, P. J. J. Org. Chem. 1988, 53, 2418. 
12. Stang, P. J.; Song, L.; Lu, Q.; Halton, B. Organometallics 1990, 9, 2149.

13. Toda, F.; Garratt, P. J. Chem Rev. 1992, 92, 1685.

14. (a) Dunams, T.; Hoekstra, W.; Pentaleri, M.; Liotta, D. Tetrahedron Lett., 1988, 29, 1745. (b) Kumar, A. Chem. Rev. 2001, 101, 1.

15. Kitamura, T.; Kotami, M.; Yokoyama, T.; Fujiwara, Y.; Hori, K. J. Org. Chem., 1999, 64, 680.

16. (a) Afarinkia, K.; Vinader, V.; Nelson, T. D.; Posner, G. H. Tetrahedron, 1992, 42, 9111. (b) Boger, D. L.; Mullican, M. D. J. Org. Chem., 1984, 49, 4033.

17. (a) Zhdankin, V. V.; Stang, P. J. Tetrahedron 1998, 54, 10927. (b) Zhdankin, V. V.; Stang, P. J. In Chemistry of Hypervalent Compounds, Akiba, K-y Ed., Wiley-VCH: New York, NY, 1999, 327. (c) Feldman, K. S.; Wrobleski, M. L. Org. Lett., 2000, 2, 2603. (d) Kitamura, T.; Tashi, N.; Tsuda, K.; Chen, H.; Fujiwara, Y. Heterocycles 2000, 52, 303.

18. Stang, P. J.; Zhdankin,V. V. J. Am. Chem. Soc., 1991, 113, 4571.

19. With ethylene glycol as solvent $\mathbf{3 b}$ provides an amorphous mass from two molecules interacting with one of solvent $(\mathrm{m} / \mathrm{z} 570)$; compound $3 c$ gives a $1: 1$ adduct $(\mathrm{m} / \mathrm{z} 376)$ under the same conditions. The structures have not been elucidated.

20. Fleming, I. Frontier Orbitals and Organic Chemical Reactions, Wiley: New York, 1976.21)Gausian 92 Revision: Gausian Inc., Pittsburg PA, USA, 1992.

21. Gausian 92 Revision: Gausian Inc., Pittsburg PA, USA, 1992.

22. SPARTAN Version 3.1: Wavefunction Inc., 18401 von Karman \#370, Irvine CA 92715, USA.

23. (a) Wilsey, S.; Houk, K. N.; Zewail, A. H. J. Am. Chem. Soc. 1999, 121, 5772. (b) Houk, K. N.; Li, Y.; Evanseck, J. D. Angew. Chem., Int. Ed. 1992, 31, 682. (c) Houk, K. N.; Beno, 
B. R.; Nendel, M.; Black, K.; Yoo, H. Y.; Wilsey, S.; Lee, J. THEOCHEM 1997, 398-399, 169. 